\title{
Practicing What We Preach: How Are Admissions Decisions Made for Clinical Psychology Graduate Programs, and What Do Students Need to Know?
}

\author{
Travis J. Pashak, Paul J. Handal, Megan Ubinger \\ Department of Psychology, Saint Louis University, Saint Louis, USA \\ Email: tpashak@slu.edu
}

Received November $15^{\text {th }}$, 2011; revised December $16^{\text {th }}$, 2011; accepted December $31^{\text {st }}$, 2011

\begin{abstract}
As the application process to Clinical Psychology graduate programs becomes increasingly competitive, applicants and advisors have a need to know what to expect. The aim of this article is to provide a brief overview of the application process, an examination of characteristics of admission committees' criteria and selection policies, and an analysis of differences among and between programs of different types. Programs offering doctoral degrees in clinical psychology $(n=59)$ were surveyed regarding their admissions procedures and criteria, and the results are discussed in light of what impacts applicants. Findings suggest that policies and procedures are mixed, that important differences exist between Ph.D. programs and Psy.D. programs, and that programs generally follow an assessment model in their selection decisions.
\end{abstract}

Keywords: Admissions; Selection; Graduate Education; Clinical Psychology

\section{Introduction}

Each year, thousands of people seek a graduate education in psychology, as it has become one of the most popular disciplines to enter. Clinical Psychology in particular is one of the largest subfields and is expected to continue to grow in popularity (Bureau of Labor Statistics, 2011). With its continued growth and popularity, the application process for clinical psychology programs has become exceptionally competitive. Because the demand for a degree in clinical psychology far surpasses the number of available positions for incoming students, the acceptance rates may cause certain anxieties in those interested in pursuing their graduate education.

In the 2003-2004 academic year, the overall acceptance rate in doctoral clinical psychology was 21.20 percent (Norcross, Kohout, \& Wicherski, 2006). This includes both Ph.D. and Psy.D. programs, and both American Psychological Association (APA)-accredited and non-accredited programs. More recently, and specific to APA-accredited programs, Norcross, Ellis, and Sayette (2010) found that acceptance rates for clinical doctoral programs averaged 17.00 percent. For comparison, Psy.D. programs had an average acceptance rate of 39.98 percent, while Ph.D. programs had an average acceptance rate of 10.25 percent. The most competitive admissions rates were found at APA-accredited Ph.D. programs with a strong research focus, averaging just 7.00 percent (Norcross, Ellis, \& Sayette, 2010).

Evidence is clear that doctoral programs in clinical psychology are highly selective. Therefore it is important for applicants and their advisors to understand the mechanisms through which these programs are making selection decisions, and to know how to successfully navigate the application journey. The goal of this article is not to provide an exhaustive set of recommendations for applicants, as effective publications of that sort al- ready exist (e.g., Sayette, Mayne, \& Norcross, 2010). Rather, the current aim is to analyze and discuss the application and admissions process generally, determine which applicant variables are deemed most important by admissions committees, investigate whether differences exist between types of clinical programs, and examine how applicant variables are interpreted.

\section{Preparing to Apply}

Before an application packet ever reaches the hands of an admissions committee, there is much effort put into preparing the materials, and it is important for prospective applicants to have a grasp on the level of commitment required of them. First, applying to graduate school requires a sizable amount of time. Many applicants are current undergraduate students in their senior year, and it has been said that the amount of work necessary to put together a successful application is approximately the equivalent of a 3-credit university course (Sayette, Mayne, \& Norcross, 2010). Further, this workload cannot reasonably be accomplished within a short period of time. Most projected timelines encourage students to spend about one year in serious preparation before mailing the applications, six months at a minimum.

In addition to the significant amount of work and time spent applying, prospective applicants need to be aware of the financial burden which will be required of them. Projected costs of applying to graduate school typically average $\$ 1500$ for a student to apply to about 12 programs (Sayette, Mayne, \& Norcross, 2010). This includes some of the more obvious costs such as paying to take the Graduate Record Exam (GRE) and paying the individual schools' application fees.

However, there are other costs which may come as a surprise to applicants. For instance, the costs of stationary, printer ink, reference books, thank-you cards for recommendation letter 
writers, and shipment charges for the packets are often overlooked when planning an application budget. The cost of traveling to interviews can vary widely depending on the distance. In addition, ETS charges a fee for each reporting of GRE scores (Educational Testing Service, 2011), colleges often charge for sending transcripts, and college career centers often utilize a surcharge for materials to be sent sealed and signed (e.g. recommendation letters). Surely, the financial aspect of graduate school applications is an issue not to be overlooked.

\section{Critical Admissions Variables}

In addition to their materials, it is important for applicants and those advising applicants to have a sense of what admissions committees are searching for and how they find it. Several studies have sought to update the understanding of critical variables in the admissions process (e.g., Norcross, Ellis, \& Sayette, 2010; Norcross, Kohout, \& Wicherski, 2006). Many researchers in the area cite the APA's Research Office's publication, Graduate Study in Psychology (American Psychological Association, 2011). This is an annual publication that presents comprehensive information on graduate programs in the United States and Canada, which are fully accredited and meet criteria to establish that the programs are psychological in nature.

Information presented in Graduate Study in Psychology includes descriptive statistics on department information, accreditation status, programs and degrees offered, student data, application and admissions statistics, faculty characteristics, financial and tuition information, GRE and GPA cut-offs, and application deadlines, all of which are collected through departmental report (American Psychological Association, 2011). There is also a table included which summarizes mean ratings of importance of various admissions criteria such as undergraduate Grade Point Average (GPA), GRE scores, and recommendation letters. The table illustrates mean ratings for ten variables, splitting the data by degree type to show differences in ratings between Master's and Doctorate level programs (American Psychological Association, 2011).

However, this publication does not provide explanations specific to psychology programs (e.g. clinical, cognitive, developmental) about how admissions boards interpret the data on their applicants. Some, but not all, programs listed indicate the relative weight placed on variables such as GRE scores or clinically related community service, with ratings of high, medium, or low. It seems likely that not only are there meaningful differences between the admissions processes of Master's and Doctorate level programs, but also between programs in various subfields. Part of the current study determined which applicant variables are generally considered the most relevant for clinical psychology admissions decisions.

\section{Clinical Training Models}

Since the APA Boulder Conference in 1949, many clinical psychology doctorate programs have endorsed the scientist-practitioner model (Baker \& Benjamin, 2000). This model holds that trainees at these institutions will gain experience in both conducting research and engaging in clinical practice with clients, all the while viewing their work through the intersecting lenses of both research and practice. Traditionally, these programs have awarded their graduates a Ph.D. degree in clinical psychology. Following the APA Vail Conference in 1973, there has been an increase in programs which endorse the practitioner-clinician model (Peterson, 1997). This model holds that trainees at these institutions will gain experience more focused on work with clients. Although these programs emphasize the importance of research-supported practice, their training is less concerned with preparation for engagement in empirical inquiry and moreso with providing a very well-rounded preparation for work with client populations. These programs have traditionally awarded their graduates a Psy.D. in clinical psychology.

As these two types of clinical psychology graduate programs have important differences in their goals and scopes for training, it follows that their admissions procedures may also have significant differences. For instance, it is expected that Psy.D. programs will tend to place more emphasis on clinical experience, while Ph.D. programs may be more attracted to applicants with stronger research experience. Part of the current study investigated these and other possible differences which may arise in the admissions procedure strategies of Ph.D. and Psy.D. programs.

\section{Applicant Data Interpretation}

Finally, an obvious concern for applicants is the strategy through which admissions boards proceed in eliminating applicants from the potential acceptance pool. A significant issue in recent decades of psychology's history is that psychologically relevant decisions should be made based upon the outcomes of assessments rather than tests. As described by Matarazzo (1990: p. 1011), an assessment is "an activity by which the clinician integrates test findings with information from the personal, educational, and occupational histories as well as from the findings of other clinicians.” By contrast, test data simply implies the numerical or qualitative result of one or more individual tests.

In order to investigate whether clinical psychology doctorate programs are testing or assessing their applicants, the question arises of whether admissions committees endorse strict GRE/ GPA cut-off scores, or consider the applicants' entire application protocol. Part of the current study determined whether testing or assessment is practiced, and with what variables.

\section{Methods}

\section{Participants}

Subjects were contacted through a recruitment letter mailed to each APA accredited Clinical Psychology program in the United States. At each program, materials including the recruitment letter and the Admissions Survey were sent to the Director of Clinical Training. The questionnaire consisted of 17 multiple-choice and rank-order items for the director or admissions chair to complete based on the current practice of the clinical program's admissions policies. Upon completion of the questionnaire, participants were asked to mail in their responses.

In total, questionnaires were sent to 210 programs, of which 155 were Ph.D. programs and 55 were Psy.D. programs. Responses led to usable data from a total of 59 programs, of which 48 were Ph.D. programs (81.36 percent) and 11 were Psy.D. programs (18.64 percent). Thus, there was a total response rate of 28.10 percent, a Ph.D. program response rate of 31.00 percent, and a Psy.D. program response rate of 20.00 percent.

Of the individuals who filled out the questionnaire, 50 were 
Directors of Clinical Training (84.75 percent) while the remaining respondents were admissions directors, admissions coordinators, or other department personnel. Twenty of the programs (33.90 percent) reported that they admit students specifically to work under a designated mentor, while 36 of the programs (61.02 percent) reported a broader admissions approach, not limiting students to a single advisor.

\section{Questionnaire Development}

The goals of the current study were essentially threefold: to investigate which applicant variables are deemed most significant in graduate psychology admissions decisions; to evaluate if those variables are considered through the lens of testing or assessment; and to determine what differences may exist between Ph.D. and Psy.D. program admissions policies. Thus, the first step was to draft a questionnaire which could sufficiently address each of those layers of inquiry.

In order to create an adequate list of potentially impactful variables in admissions decisions, the authors referenced the findings from Graduate Study in Psychology (American Psychological Association, 2011) and also included some additional items. Some criteria to be considered were objective (e.g. GRE scores, undergraduate GPA, psychology GPA) while others were subjective (e.g. personal statement, match to faculty interests, and performance on interviews). Further, some variables were based on work ethic and passion for the science of psychology (e.g. clinical experience, research experience, research publications) while others focused on the individual's background (e.g. volunteer work, diversity factors such as re- ligion and ethnicity, and undergraduate university). These and other potentially important criteria were compiled into a list of 15 variables to help determine which are most impactful for graduate admissions decision-making. To do so, each program was asked to rank-order each variable so that ultimately, a mean rank-score could be achieved for each.

Designing items for the other two aims of the study was less involved. For investigating differences between Ph.D. and Psy.D. programs, an item was included to differentiate which degree a program granted its students. To determine if testing or assessment was employed by admissions committees, several items were drafted to address whether strict cut-offs were utilized for the objective variables of undergraduate GPA and GRE score (and if so, participants were asked what those cutoff scores were). If cut-offs were present, another item assessed what was done with applicants who fell below the cut-point (specifically, were applications below cut-offs outright rejected, considered in light of other factors, or retained for further deliberation). The Admissions Survey is included as Appendix 1.

\section{Results}

\section{Critical Variables}

In order to assess the value placed on variables in the admissions process, rank-ordering was done on a list of 15 variables. Table 1 depicts the mean (M), standard deviation (SD), and minimum and maximum ranks of each variable (Min, Max), as well as t-values and mean differences (Md) regarding the significant differences between Ph.D. and Psy.D. programs.

Table 1.

Admissions variable rankings.

\begin{tabular}{|c|c|c|c|c|c|c|c|c|c|c|}
\hline \multirow[b]{2}{*}{ Admissions Variable } & \multicolumn{4}{|c|}{ Ph.D. Program } & \multicolumn{4}{|c|}{ Psy.D. Program } & \multicolumn{2}{|c|}{ Difference } \\
\hline & M & $\mathrm{SD}$ & Min & Max & M & $\mathrm{SD}$ & Min & Max & t-value & $\mathrm{Md}$ \\
\hline Undergrad GPA & 4.55 & 3.84 & 1 & 15 & 2.60 & 1.78 & 1 & 7 & 2.359 & $1.95^{*}$ \\
\hline Major GPA & 8.28 & 4.41 & 1 & 14 & 7.38 & 4.96 & 1 & 14 & 0.512 & 0.903 \\
\hline Junior-Senior GPA & 7.76 & 4.89 & 1 & 15 & 9.25 & 4.92 & 1 & 14 & -0.782 & -1.49 \\
\hline GRE Score & 3.29 & 2.82 & 1 & 13 & 3.56 & 4.61 & 1 & 15 & -0.224 & -0.26 \\
\hline Psych Subject GRE & 9.81 & 4.07 & 1 & 15 & 9.71 & 5.79 & 2 & 15 & 0.040 & 0.09 \\
\hline Personal Statement & 5.88 & 2.77 & 1 & 14 & 4.80 & 2.70 & 1 & 9 & 1.109 & 1.08 \\
\hline Site Specific Essay & 11.84 & 4.00 & 1 & 15 & 11.00 & 2.92 & 8 & 15 & 0.448 & 0.84 \\
\hline Research Match & 4.85 & 3.40 & 1 & 13 & 12.57 & 2.51 & 9 & 15 & -5.718 & $-7.72^{* * * *}$ \\
\hline Diversity & 7.89 & 3.48 & 1 & 15 & 8.25 & 2.44 & 5 & 13 & -0.278 & -0.36 \\
\hline Interview & 6.29 & 3.40 & 1 & 13 & 4.44 & 2.19 & 1 & 8 & 1.547 & 1.85 \\
\hline Clinical Experience & 8.97 & 3.35 & 2 & 14 & 5.13 & 2.42 & 2 & 9 & 3.074 & $3.849^{* *}$ \\
\hline Research Experience & 4.66 & 2.83 & 1 & 13 & 8.75 & 4.17 & 3 & 14 & -2.660 & $-4.09^{*}$ \\
\hline Volunteer Experience & 12.06 & 2.31 & 5 & 15 & 9.13 & 2.80 & 4 & 11 & 3.114 & $2.93^{* *}$ \\
\hline Research Publications & 8.27 & 3.57 & 2 & 14 & 11.86 & 2.27 & 7 & 13 & -2.547 & $-3.59^{*}$ \\
\hline Undergrad University & 9.26 & 3.91 & 1 & 15 & 10.50 & 4.63 & 2 & 15 & -0.785 & -1.24 \\
\hline
\end{tabular}

${ }^{*} p<0.05 ;{ }^{* *} p<0.01 ;{ }^{* * *} p<0.001$. 
Inspection of Table $\mathbf{1}$ reveals several noteworthy findings. First, a somewhat surprising result is that each of the 15 variables received a wide range of ranks from both types of program. Especially within the Ph.D. programs, it appears that nearly every variable was valued both most and least by one of the respondents. This indicates that there was considerable variability, even within program types, regarding the import of each admissions variable.

Despite the high variability, the results indicate that there were several factors clearly valued highest. For Ph.D. programs, the top five ranked variables (in order starting with the most valued) were as follows: GRE score, undergraduate GPA, research experience, research match, and personal statement. Meanwhile, Psy.D. programs ranked the following as the top five variables: undergraduate GPA, GRE score, interview, personal statement, and clinical experience. Thus, it appears that a student's undergraduate GPA and GRE score were uniformly the two most valued criteria for admissions. Further, a student's personal statement was ranked within the top five variables for both types of programs.

\section{Program Differences}

While GPA, GRE, and personal statements ranked as highly valuable across program types, there were also meaningful differences in ranks which became apparent. For instance, two of the top five ranked variables did not match between Ph.D. and Psy.D. programs. In Ph.D. programs, the uniquely valued variables were research experience and a research match between the applicant and available mentors. For Psy.D. programs, the uniquely valued variables were the applicant's interview performance and clinical experience.

The fact that Ph.D. programs valued research productivity and research-mentor fit while Psy.D. programs valued clinical experience and positive interview performance would likely be expected, but other differences appeared that may not have been so obvious. For instance, Psy.D. programs ranked volunteer experience as statistically significantly more valuable than did Ph.D. programs. However, for the most part, significant differences between variable rankings seem to represent pragmatic differences in the training and educational goals associated with each type of graduate program.

\section{Testing versus Assessment}

In order to examine whether admissions boards are engaged in testing versus assessment, several items were utilized to evaluate the presence and function of cut-off scores. A total of 27 of the 59 programs reported utilizing a GPA cut-off (45.76 percent) and 19 programs reported utilizing a GRE cut-off score (32.20 percent). Together, the majority of programs employed at least one cut-off (32 of the 59 programs; 52.54 percent) while the remaining 27 programs did not use any cut-offs (45.76 percent).

Perhaps more important than the presence of cut-offs then, is how admissions boards treated the applications which did indeed fall below the minimum requirements. Only 4 programs (3 Ph.D. programs and 1 Psy.D. program; 6.78 percent) reported that they rejected an applicant outright if his or her GPA and/or GRE scores fell below the designated cut-off. All other programs (55 of the 59; 93.22 percent) reported that they reviewed the file and considered other factors which might mitigate low
GPA and/or GRE scores. Thus, the minority of programs are essentially engaging in what could be referred to as testing, using GPA and/or GRE scores as crucial criteria. The majority of clinical psychology doctorate programs, then, are evaluating applicants based on an assessment model.

\section{Discussion}

The current study set out to answer three main questions: what variables are most important in the decision-making process for APA-accredited doctoral-level clinical psychology program admissions boards; are there meaningful differences in the valuing of applicant variables between Ph.D. and Psy.D. programs; and are the admissions boards carrying out their decisions through a testing strategy or through an assessment-like fashion. The results of the survey showed that there were indeed patterns of which variables are more or less valued, there were meaningful differences between Ph.D. and Psy.D. admissions procedures, and most programs did indeed assess applicants.

So what can today's aspiring clinical psychologist make of these results? First and foremost, it appears that there are three criteria which are of utmost importance regardless of the type of program students are aiming toward: undergraduate GPA, GRE scores, and personal statements. Thankfully, these are three criteria which are largely within an applicant's control. Whatever strategies may positively impact GPA would thus be advisable, including the use of tutoring services, taking advantage of personal meetings with professors during office hours, and seeking out effective study groups. Regarding GRE scores, it would thus seem advisable to do an adequate amount of preparation before taking the test, re-take the test if necessary, and seek preparatory courses for the GRE. Many college campuses abound with preparation courses for the GRE as well as other similar tests (e.g. MCAT, LSAT). Finally, the high value placed on a student's personal statement necessitates that applicants put forth their best writing efforts and utilize all resources available to them. Applicants are urged to pay very careful attention to the instructions provided by programs for the personal statements they expect-as each may differ slightly. Application guides often cite strategies such as tailoring each personal statement specifically to each program, utilizing the terminology found in an institution's mission statement, and referencing matches in interest with potential mentors (e.g. Sayette, Mayne, \& Norcross, 2010). Overall, the personal statement would ideally reflect more than simply a match in research interests. It would illustrate a match between the applicant and the mission and atmosphere of the university, as well as the training philosophy of the clinical psychology program.

Regarding differences between the Ph.D. and Psy.D. programs, it appears that students aiming toward a Ph.D. program should surely focus on their preparation and presentation of research experience, research publications, and a formulation of their research interests which matches nicely with a program's faculty member(s). For students aiming toward a Psy.D. program, it seems that clinical experience, an impressive in-person interview, and volunteer experience are more valued variables. Although all of the variables discussed are potential deciding influences for either type of program, it is important that applicants have a sense of what might be their best attribute when presenting themselves in person or in the form of application 
packets.

Finally, regarding how these applicant variables are interpreted, results showed that over half of the doctoral programs in clinical psychology engage in some use of cut-offs for GPA and/or GRE scores. However, when asked how those cut-offs were used, it appears that the vast majority of programs did not utilize them in an overly strict way. In fact only rarely did programs report that an applicant below a cut-off would be completely rejected immediately. Conversely, the majority of programs indicated that they take care to consider other applicant variables before making any rejection decisions on scores alone.

This tendency toward assessment bodes well on both sides of the envelope: it thus appears that clinical psychology admissions boards are practicing what the field preaches in regard to the value of comprehensive assessments for significant decision-making, and applicants can remain hopeful if they have an aspect of their protocol which is less competitive than others. The results presented appear to provide evidence that applicants concerned about falling below a cut-off should not immediately remove programs from their application lists so long as they feel that their other qualifications may be mitigating and deemed positive and desirable. For example, a Ph.D. applicant with a GPA below an institution's cut-off may still prove to be a competitive candidate if he or she carries a strong GRE score, has written a well-tailored personal statement, and has an impressive array of research experiences (particularly if the applicant has one or more presentations/publications which match the available mentors' interests).

\section{Limitations}

It is worth noting that although the results reported in this study could be very informative for applicants and their advisors, the response rate from the graduate programs surveyed was somewhat low. While the balance of representation between Ph.D. and Psy.D. programs remained intact, only 21.80 percent of the programs contacted responded to the survey. This could potentially lead to issues of response bias. However, it appears that the results reported here are congruent with the mission and goals of Ph.D. and Psy.D. programs.

\section{REFERENCES}

American Psychological Association (2011). Graduate study in psychology 2011. Washington DC: American Psychological Association.

Baker, D. B., \& Benjamin, L. T. Jr. (2000). The affirmation of the scientist-practitioner: A look back at Boulder. American Psychologist, 55, 241-247.

Bureau of Labor Statistics (2011). Psychologists. In Occupational outlook handbook, 2010-11 Edition. Retrieved from http://www.bls.gov/oco/ocos056.htm

Educational Testing Service (2011). Sending your scores. In GRE general test. Retrieved from http://www.ets.org/gre/general/scores/send

Matarazzo, J. D. (1990). Psychological assessment versus psychological testing: Validation from Binet to the school, clinic and courtroom. American Psychologist, 45, 999-1017. doi:10.1037/0003-066X.45.9.999

Norcross, J. C., Ellis, J. L., \& Sayette, M. A. (2010). Getting in and getting money: A comparative analysis of admission standards, acceptance rates, and financial assistance across the research-practice continuum in clinical psychology programs. Training and Education in Professional Psychology, 4, 99-104. doi:10.1037/a0014880

Norcross, J. C., Kohout, J. L., \& Wicherski, M. (2006). Graduate study in psychology: 1971 to 2004. American Psychologist, 60, 959-975. doi:10.1037/0003-066X.60.9.959

Peterson, D. R. (1997). Need for the doctor of psychology degree in professional psychology. In D. R. Peterson, (Ed.), Educating professional psychologists: History and guiding conception (pp. 65-75). Washington DC: American Psychological Association. doi:10.1037/10229-004

Sayette, M. A., Mayne, T. J., \& Norcross, J. C. (2010). Insider's guide to graduate programs in clinical and counseling psychology. New York, NY: The Guilford Press. 


\section{Appendix 1}

\section{Admissions Survey}

Instructions: The following items refer to the admissions procedures of your graduate clinical psychology program. Please circle the letter corresponding with your response to each item. If more than one response seems to be applicable, please choose the one that best applies to your program.

1. What is the position of the individual who completed this form?

a. Director of Clinical Training

b. Director of Admissions

c. Admissions Coordinator

d. Other (Please specify

2. What degree is conferred from this program?
a. Ph.D.
b. Psy.D.
c. Other

3. Are students admitted to the program by a specific faculty member to work with them?
a. Yes
b. No

4. Please rank all of the following items $(1-15)$ in terms of your program's consideration of them in its admissions procedures:

a. ___ Undergraduate Grade Point Average (GPA)

b. __ Undergraduate Major GPA

c. Junior \& Senior Year GPA

d. __ Graduate Record Exam (GRE) Scores

e. Psychology Subject Test GRE Scores

f. Personal Statement

g. Site-specific Essays

h. Match to Faculty Research Interests

i. __ Diversity (Age, Sex, Sexual Orientation, Religion, Race, and Ethnicity)

j. Interview

k._ Clinical Experience

1.__ Research Experience

m._ Volunteer Experience

n. Research Publications

o. Undergraduate University

5. Regarding your program's use of Undergraduate GPA, do you employ a cut-off score?
a. Yes
b. No

6. If you answered yes to number 5 , is your cut-off:
a. 3.0
b. 3.5
c. 3.7
d. Other

7. Regarding your program's use of GRE scores, do you employ a cut-off score?
a. Yes
b. No

8. If you answered yes to number 7, is your cut-off:

a. Combined Verbal and Quantitative 1000

b. Combined Verbal and Quantititave 1200

c. Other

9. Based on your program's cut-off criteria, is an application rejected if:
a. It falls below both GPA and GRE cut-off score
b. It falls below either the GPA and GRE cut-off score

10. If an application falls below either/both GPA and GRE cut-off scores, is it:

a. Rejected

b. Reviewed using additional factors (letters of recommendation, statement of intent, etc.) for exceptions to the cut-offs employed

c. Kept for potential future review/consideration

11. Does your program employ a statistical regression model to aid in the admissions decision process?
a. Yes
b. No

12. How many faculty members are on your program's admissions committee?
a. 0 - 3
b. 4 - 6
c. $7+$

13. Of the faculty on the admissions committee, how many are clinical program faculty?
a. $0-2$
b. $3-5$
c. Other

14. How many faculty members review each application that is submitted?
a. 0 - 2
b. $3-5$
c. Other

15. When reviewing applications, do the faculty reviewers employ standardized criteria?
a. Yes
b. No

16. Approximately how many students are admitted to your clinical psychology program annually?
a. 0 - 2
b. $3-5$
c. 6 - 8
d. Other

17. Does your program reserve places for individuals who apply with a Master's degree?

$$
\text { a. Yes (If so, how many? }
$$

b. No

Thank you for your time and assistance with this project. 